\title{
Colony-colony interactions between highly invasive ants
}

\author{
Cleo Bertelsmeier ${ }^{\mathrm{a}, *}$, Sébastien Ollier ${ }^{\mathrm{a}}$, Amaury Avril ${ }^{\mathrm{a}}$, Olivier Blight ${ }^{\mathrm{b}}$, \\ Hervé Jourdan ${ }^{c}$, Franck Courchamp ${ }^{\mathrm{a}}$ \\ ${ }^{a}$ Ecologie, Systématique \& Evolution, UMR CNRS 8079, Univ. Paris Sud, Orsay Cedex 91405, France \\ ${ }^{\mathrm{b}}$ Estación Biológica de Doñana, Consejo Superior de Investigaciones Científicas, 41092 Sevilla, Spain \\ 'Institut Méditerranéen de Biodiversité et d'Écologie marine et continentale (IMBE), Aix-Marseille Université, \\ UMR CNRS - IRD - UAPV, Centre IRD Nouméa, BP A5, 98848 Nouméa Cedex, New Caledonia
}

Received 1 April 2015; accepted 14 September 2015

Available online 21 October 2015

\begin{abstract}
Among invasive species, ants are a particularly prominent group with enormous impacts on native biodiversity and ecosystem functioning. Globalization and on-going climate change are likely to increase the rate of ant invasions in the future, leading to simultaneous introductions of several highly invasive species within the same area. Here, we investigate pairwise interactions among four highly invasive species, Linepithema humile, Lasius neglectus, Pheidole megacephala and Wasmannia auropunctata, at the whole colony level, using a laboratory set-up. Each colony consisted of 300 workers and one queen. The number of surviving workers in the competing colonies was recorded daily over 7 weeks. We modelled the survival of each colony during pairwise colony interactions, using a nonlinear model characterizing the survival dynamics of each colony individually. The least dominant species was $P$. megacephala, which always went extinct. Interactions among the three other species showed more complex dynamics, rendering the outcome of the interactions less predictable. Overall, W. auropunctata and L. neglectus were the most dominant species. This study shows the importance of scaling up to the colony level in order to gain realism in predicting the outcome of multiple invasions.
\end{abstract}

\section{Zusammenfassung}

Unter den invasiven Arten sind Ameisen eine ganz besonders auffällige Gruppe mit enormen Auswirkungen auf heimische Arten und Ökosystemfunktionen. Die Globalisierung und anhaltender Klimawandel werden wahrscheinlich in der Zukunft die Rate an Ameiseninvasionen erhöhen, was zu simultanen Einführungen von mehreren invasiven Arten in der gleichen Region führen kann. Hier untersuchen wir paarweise Interaktionen zwischen vier hoch invasiven Arten, Linepithema humile, Lasius neglectus, Pheidole megacephala und Wasmannia auropunctata, indem wir Konfrontationen zwischen ganzen Kolonien in einem Laborversuch durchführen. Jede Kolonie bestand aus 300 Arbeiterinnen und einer Königin. Die überlebenden Arbeiterinnen in konkurrierenden Kolonien wurden täglich über einen Zeitraum von sieben Wochen gezählt. Wir haben die Überlebensrate je Kolonie während der paarweisen Interaktionen modelliert, indem wir die Koloniedynamik mit einem nichtlinearen Model charakterisierten. Die am wenigsten dominante Art war P. megacephala, welche immer ausgestorben ist. Die Interaktionen zwischen den restlichen drei Arten zeigten eine komplexere Dynamik, die das Ergebnis der Interaktionen weniger vorhersehbar machte. Insgesamt waren W. auropunctata und L. neglectus die dominantesten Arten. Diese Studie zeigt die Bedeutung von

\footnotetext{
${ }^{*}$ Corresponding author. Present address: Department of Ecology and Evolution, Biophore, Quartier UNIL-Sorge, University of Lausanne, 1015 Lausanne, Switzerland. Tel.: +41 21692 4218; fax: +41 216924165 .

E-mail address: cleo.bertelsmeier@gmail.com (C. Bertelsmeier). 
Experimenten auf dem Kolonie-Niveau, um realistischere Ergebnisse zu bekommen und das Resultat multipler Invasionen vorhersagen zu können.

(C) 2015 Gesellschaft für Ökologie. Published by Elsevier GmbH. All rights reserved.

Keywords: Biological invasions; Invasive ants; Colony behaviour; Interference competition; Colony survival; Linepithema humile; Lasius neglectus; Pheidole megacephala; Wasmannia auropunctata

\section{Introduction}

On-going globalization and tourism facilitate species movements across the world and the rates of new species introductions are exploding (Essl et al., 2011). As a result, biological invasions are increasingly threatening biodiversity. Among invasive species, ants (Formicidae) are a particularly prominent group. Owing to their small size, they can be easily transported by accident on plants, fresh products, timber, shipment containers or personal items (Suarez, Holway, \& Ward, 2005). More than 200 ant species have been transported by humans and introduced outside their native range (Suarez, McGlynn, \& Tsuitsui, 2010), but there are potentially even more exotic ant species which have established outside of their native range (Miravete et al., 2014). A subset of these exotic species has become invasive and has enormous impacts on native biodiversity, ecosystem functioning and animal or human health (Holway, Lach, Suarez, Tsutsui, \& Case, 2002; Lach \& Hooper-Bui, 2010; Rabitsch, 2011). In addition, many species can invade houses, destroy electrical equipment and impact agriculture, causing high economic losses (Pimentel, Zuniga, \& Morrison, 2005). A total of 19 species has been listed as highly invasive by the IUCN invasive species specialist group (IUCN SSC Invasive Species Specialist Group, 2012) and 5 species are even on the IUCN "100 of the world's worst invasive alien species" list (Lowe, Browne, Boudjelas, \& De Poorter, 2000). Very few native species have been shown to be able to resist the most harmful invasive ant species (e.g. Masciocchi, Farji-Brener, \& Sackmann 2009; Blight, Provost, Renucci, Tirard, \& Orgeas 2010; Cerdá, Angulo, Caut, \& Courchamp 2012). Invasive ants are frequently very aggressive and behaviourally dominant species (Holway et al., 2002). Interference competition between invasive and native ant species is relatively well studied, but interactions between invasive ant species remain poorly known. It is unclear how two invasive ant species would interact, should they be simultaneously introduced within the same area. Generally, in regions where multiple invasions have occurred, invasive ants do not co-exist in the same area (Lebrun \& Feener, 2007; Krushelnycky \& Gillespie, 2010; Spicer Rice \& Silverman, 2013). A recent modelling study has identified large uninvaded areas that may be suitable for 15 of the 'worst' invasive ants (Bertelsmeier, Luque, Hoffmann, \& Courchamp, 2015b). The suitable range of several highly invasive ants overlaps substantially, creating large potential invasion "hotspots". However, predictive species distribution modelling does not take into account biotic interactions (Guisan \& Thuiller, 2005). Therefore it is important to investigate whether a single top dominant ant species may ultimately prevail, displacing other aggressive, yet less competitive invasive species.

Classically, species interactions have been investigated in community studies, using pitfall traps to record the numerical dominance of different species and with baits to observe behavioural interactions (Cerdá, Arnan, \& Retana, 2013). In the case of interactions between multiple invasive ant species, this is not possible because they usually do not co-occur in the same areas yet, although they may interact in the future. To circumvent this difficulty, studies have used behavioural assays under laboratory conditions, placing one or several workers of different species in a petri dish and recording their interactions. Several previous studies on behavioural interactions have carried out this type of laboratory experiments, yet it remains rare in the literature on interference competition (Buczkowski \& Bennett, 2008; Blight et al., 2010), especially among invasive ants (but see Kirschenbaum \& Grace, 2008). However, these interference experiments in petri dishes are based on single worker interactions and it is unclear whether results from these experiments can be extrapolated to the colony level (but see Holway and Suarez, 2004 for an experimental colony confrontation between the Argentine ant and a native competing species). For example, the low number of workers used (either single workers or groups of 10-25) does not allow species to display interference strategies depending on a minimum number of workers (Buczkowski \& Bennett, 2008). Further, the presence of resources or a territory is known to influence behaviours, and thus dominance hierarchies (Tanner \& Adler, 2009). Clearly, experiments under more realistic conditions are needed - at the whole colony level in the presence of a queen and over an intermediate to long time span.

Here, we investigate the dominance relationships of four of the worst invasive ant species (Linepithema humile, Lasius neglectus, Pheidole megacephala and Wasmannia auropunctata, see Appendix A, Table S1 for details on these species), using dyadic interactions at the colony-level. These species might colonize the same areas in the future, according to a recent modelling study (Bertelsmeier et al., 2015b). To increase realism, we provided the species with sufficient space to avoid confrontations (unlike the small petri dishes) and we monitored the survival daily over 6 weeks. 


\section{Material and methods}

\section{Colony collection and maintenance of laboratory colonies}

The ants were collected between March and May 2012 in New Caledonia (W. auropunctata, P. megacephala) and in Southern France (L. humile and L. neglectus) (for details on colony collection, please see Appendix A, Table S2). The interactions were conducted in June and July 2012. Colony fragments were maintained in plastic nest containers $(55 \times 35 \times 25 \mathrm{~cm})$ filled with substrate from the original nesting site (soil, wood, leaves) and contained several tubes of water. The boxes were kept at $24 \pm 2{ }^{\circ} \mathrm{C}$ with the appropriate soil moisture. The ants were fed daily with a variant of the Bhatkar diet (Dussutour \& Simpson, 2008) and ad libitum during the interactions. All colonies were kept under these laboratory conditions for at least one month, with little mortality $(<5 \%$ in all colonies over the duration of the acclimation) and produced brood, indicating that all colonies were in good health before the start of the experiment and no mortality was observed due to the laboratory rearing conditions.

\section{Colony-colony interactions}

We tested pairwise colony interactions among four species, W. auropunctata, L. neglectus, L. humile and P. megacephala (i.e., 6 pairwise interactions). Each pairwise interaction was replicated five times, except the interaction $L$. humile $-L$. neglectus, which was replicated 6 times. Each colony consisted of 300 workers and one queen. Colonies of P. megacephala, which was the only species to possess two worker castes, contained $10 \%$ soldiers and $90 \%$ minor workers (following Kirschenbaum \& Grace, 2008). Each colony was placed in a foraging arena $(18 \times 12 \times 7 \mathrm{~cm})$ with a plaster bottom and a metal mesh fused to several holes on the top lid for aeration. The foraging arena was connected to a nest tube ( $1 \mathrm{~cm}$ in diameter and $10 \mathrm{~cm}$ long), which was divided by a piece of cotton into a nesting space (adjacent to the foraging arena) and a water source. The nest tube was covered with a red filter in order not to disturb the ants in the nest but to be able to count individuals in the tube. The foraging arenas of the two interacting colonies were connected via a plastic tube (see Appendix A, Fig. S1). After placing the colonies in their respective arenas, they were allowed to acclimatize and move to the nesting tubes for $24 \mathrm{~h}$. After that, the connecting tube was unblocked by removing the obstructing piece of cotton, thereby allowing the two adjacent colonies to interact. During the first hour after connection, the number of fights in both arenas (incursions) was recorded every $10 \mathrm{~min}$. Afterwards, we monitored the fights every hour over $5 \mathrm{~h}$. Subsequently, fighting was only rarely observed and we recorded daily the number of surviving individuals of interacting species, over 42 days.

\section{Data analyses}

\section{Incursions}

Prior to statistical analysis of the results, we examined all data distributions using the Shapiro Wilk $W$ test for normality. Because residuals of the data did not conform to a normal distribution, we used the nonparametric Mann-Whitney test to test for differences in mean incursions in pairs of species and the Kruskal-Wallis rank sum test to compare mean incursions across interactions. We then tested the correlation (Spearman) between the difference in incursions between pairs of species and the difference in mortality between pairs of species.

\section{Colony survival}

We modelled the survival of each colony during pairwise colony interactions, using a nonlinear model:

$n(t)=e^{-a t+\log (d-p)}+p$

where $n(t)$ is the number of surviving workers at time $t, d$ is the asymptotic value at $t_{0}$, which is the first point of the curve, $a$ is the steepness of the slope of the function describing the colony decline and $p$ is the asymptotic limit when $t$ tends towards infinity (i.e., the final colony size after 42 days of observation).

Because of a steep decline after the initial fights following the connection of the two adjacent arenas, we chose to set $t_{0}$ at day 1 , so that $d$ represents the number of workers that survived the initial confrontation during day 0 , thereby giving a measure of the number of workers lost during the first interaction.

In other words, the trend of each colony is summarized through three parameters only: the importance of the initial decline $(d)$, the speed of the subsequent decline $(a)$ and the final colony size $(p)$. More competitive colonies are expected to have a high $d$, a low $a$ and/or a high $p$. Competitive performance of colonies can be visualised through their values of these three parameters and the positions of each colony in the $p-d-a$ parameter space can be compared. In order to simplify the representation, we prepared the representation in $2 \mathrm{D}$ (plane $d-p$ ), with the parameter $a$ being represented by the size of the data point (see an example in Fig. 1B).

Based on estimations of the errors of the estimated model parameters, confidence envelopes for each model in a parameter space were calculated and represented in 2D (Fig. 1), following Beale (1960). The parameters are estimated using the function nls() in R v.2.15.2, using the algorithm 'port' which allows constraining the values of $d$ to 300 and the values of $p$ to 0 .

In the following representations, we decided not to show the confidence envelopes because they almost never overlap and render the visual representation of the data unnecessarily complex. 
(A)

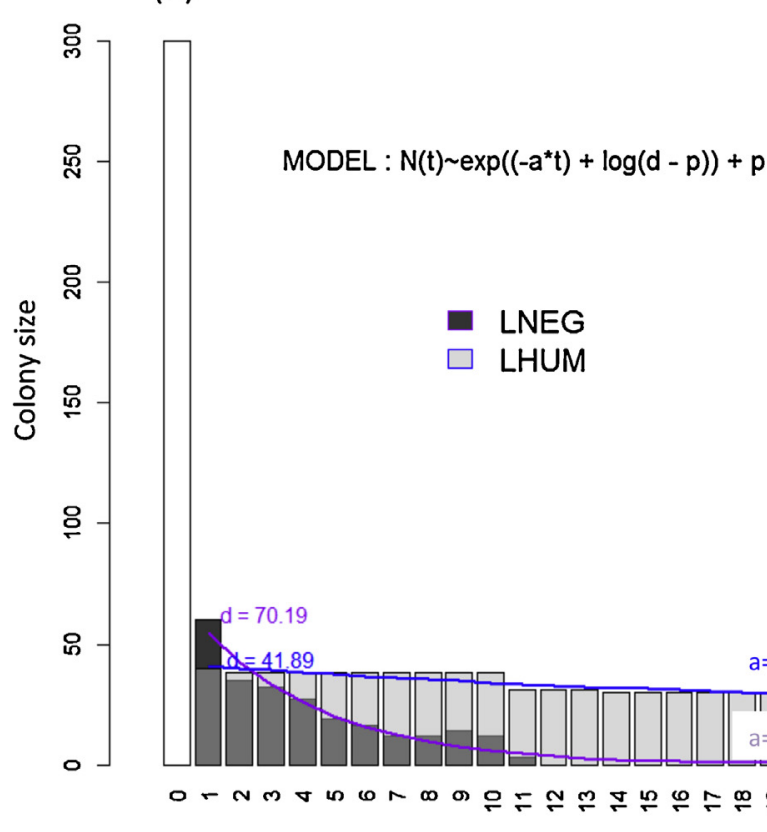

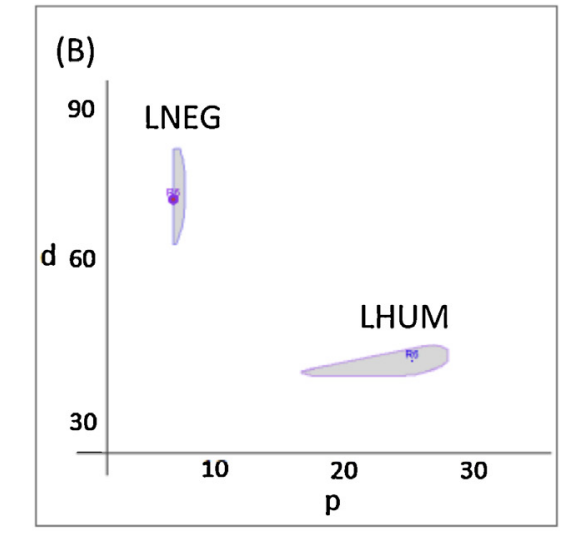

(B)

$a=0.05$

$a=0.25$

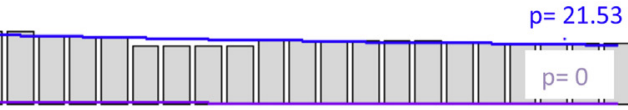

Time (days)

Fig. 1. (A) Example of fitted models for the survival of two colonies in replicate 6 of the interaction L. neglectus (LNEG) against $L$. humile (LHUM). The grey histograms represent the raw data, the colony size at time $t$ (dark L. neglectus, light $L$. humile) and the two lines correspond to the models fitted for each species (purple L. neglectus, blue L. humile). Although L. neglectus has a lower initial decline, it then declines faster, down to extinction. In contrast, $L$. humile declined more the first day of the interaction, but then declined very slowly and ended up surviving with two dozen individuals. (B) Representation of the two models in 2D parameter space $d-p$, with the size of the data points representing parameter $a$. If the points are coloured in red, extinction has occurred. Confidence envelopes of the estimated parameters are represented in light grey, with the colour of the contour corresponding to the opponent species. This shows clearly that $L$. neglectus, despite a higher initial surviving size, ends up at zero because of a steep subsequent decline, while L. humile survived, thanks to a more gradual decline.

Then, we performed a classification analysis, using the Euclidean distance between points in parameter space with the hclust() function in R. This classification analysis defines groups of colonies with similar survival processes.

\section{Results}

\section{Incursions}

During colony-colony interactions, the mean number of incursions into the arena of the opponent differed between species (Kruskal Wallis test: $\left.\chi^{2}(3)=41.2, p<0.0001\right)$. $L$. humile made the most incursions and $W$. auropunctata the least. Because of the differences in the number of incursions, there was a tendency for fights to take place rather in one arena than the other across the following species pairs: P. megacephala-L. neglectus $\left(\chi^{2}(1)=52.1, p<0.0001\right)$, $W$. auropunctata-L. neglectus $\left(\chi_{(1)}^{2}=7.1, p=0.0078\right), L$. humile-W. auropunctata $\left(\chi_{(1)}^{2}=6.9, p=0.0088\right)$ and $P$. megacephala-W. auropunctata $\left(\chi^{2}(1)=7.0, p=0.0082\right)$. The difference in the number of incursions was negatively correlated to the difference in final survival (Pearson $r^{2}=0.521$, $p<0.001, n=31$ ).

\section{Colony survival}

The fitted models showing the declining colony size over 42 days of the experiment reveal that survival processes vary among species combinations but also (if less drastically) among replicates of the same species combination (Fig. 2).

When the estimated model parameters are represented in parameter space (Fig. 3), different groups can be distinguished. Each replicate number of a particular species pair appears twice: once for species A, once for species B. For example R4 of the interaction WAUR-PMEG appears once within the orange group 'PMEG-waur' representing the colony dynamics of $P$. megacephala in this replicate. R4 appears again in the green group 'WAUR-pmeg' representing the colony dynamics of $W$. auropunctata in the same interaction experiment. We did not present queen survival in this analysis because queens did not participate in the confrontations and were almost always the last individual in the colony to die. In only three colonies, the queen was among the last 5 individuals.

All replicates of $P$. megacephala colonies (yellow points) have very high $d$ values and $p$ values equalling 0 (relatively high initial survival but extinction at the end). Similarly, almost all colonies of $L$. humile (blue points) went extinct 

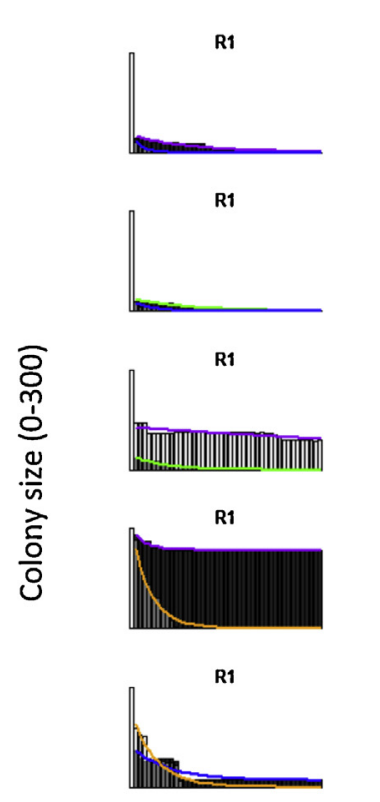

R1

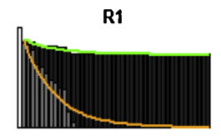

R2

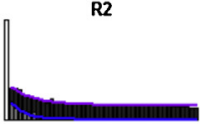

R2

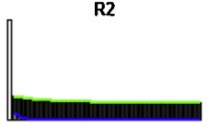

$\mathbf{R 2}$

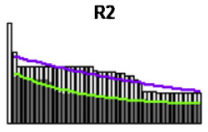

$\mathbf{R 2}$

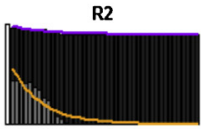

$\mathbf{R 2}$

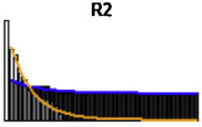

R2

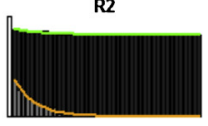

R3

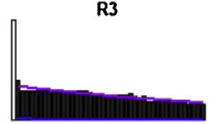

R3

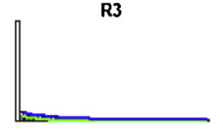

R3

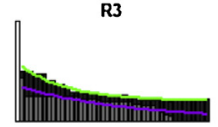

R3

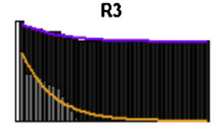

R3

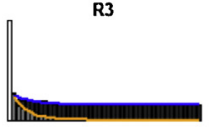

R3

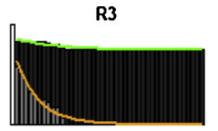

R4

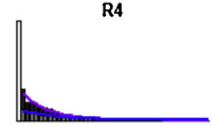

R4

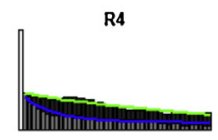

R4

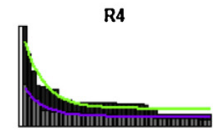

R4

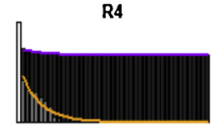

R4

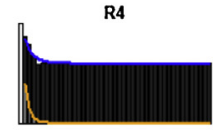

R4

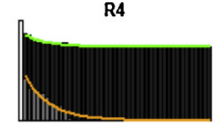

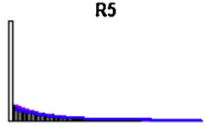

R5

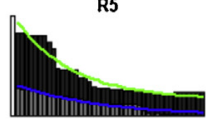

R5

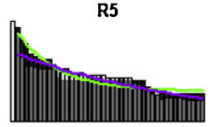

R5

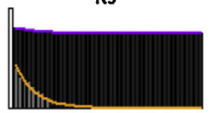

R5
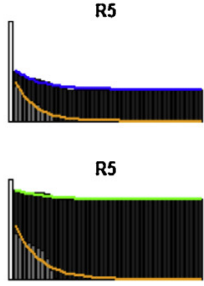

R6

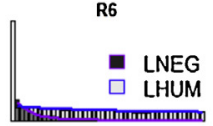

- WAUR

$\square$ LHUM

- WAUR $\square$ LNEG

- LNEG $\square$ PMEG

- LHUM $\square$ PMEG

- WAUR

Time in days (0-43)

Fig. 2. Colony survival (grey bars) and fitted model functions (coloured lines) for all replicates of all pairwise species interactions. Each row represents the replicates (R1-R6) of the same species interaction. $\mathrm{LNEG}=$ L. neglectus, $\mathrm{LHUM}=$ L. humile, WAUR $=$ W. auropunctata, $\mathrm{PMEG}=$ P. megacephala .

$(p=0)$, except against $P$. megacephala. This indicates dominance of $L$. humile over $P$. megacephala only. In the interactions between $L$. humile and L. neglectus, both species suffer high initial mortality (low $d$ ) and have a very low final colony size (low $p$ ), but both parameters are slightly higher in L. neglectus. Additionally, the mortality parameters for $L$. neglectus faced with $P$. megacephala are much higher than those of $L$. humile against $P$. megacephala, also indicating that overall $L$. neglectus has a slight competitive advantage over L. humile. Overall, W. auropunctata (green points) was the top dominant species with very high survival against $P$. megacephala and relatively high $d$ and $p$ values against L. humile and L. neglectus. Although a general hierarchy can be established among the species (W. auropunctata/L. neglectus $>$ L. humile $>P$. megacephala), colony dynamics were variable among replicates. In addition, there was a considerable inter-specific variability in terms of survival processes. In particular, P. megacephala and L. humile colonies typically went extinct by the end of the experiment. However, P. megacephala resisted much better than L. humile during the first few days of the confrontation, (higher $d$ ).

The classification analysis reveals seven groups with a similar survival process, which do not necessarily correspond to the same species (Fig. 4). In contrast to groups 1-3, extinction occurs in groups 4-7. Among the other groups, group 1 has a low $p$ and a low $d$, i.e. it has a small initial decline and stabilizes at a low level but without going extinct. In this group, three species are represented, W. auropunctata, L. humile and L. neglectus. Group 2 (only W. auropunctata and L. neglectus) has also a small $p$, but a higher $d$ value, i.e. a good initial resistance and stabilization of the colony size at a low level. Group 3 (only W. auropunctata and L. neglectus) has both a high $d$ and a high $p$ : it resists well initially and stabilizes at a large colony size. Among the groups where extinction occurred, there are two different types of patterns. Either, the initial decline is large (low $d$ ) and the extinction occurs more (groups 4 and 6) or less (group 5) rapidly, or the initial decline is low and the decrease occurs more progressively, down to extinction (group 7). Group 7 is also notable because it comprises only $P$. megacephala and almost all interactions concerning this species.

\section{Discussion}

Connecting foraging arenas of species among four of the most invasive ants, W. auropunctata, L. neglectus, L. humile and $P$. megacephala, resulted in immediate aggressive interactions in all cases. After intense fighting over the first hours following colony connection, fragments of both colonies survived and declined progressively over the 42 days of observation. In these experiments, the least dominant species was $P$. megacephala, which always went extinct, although its 


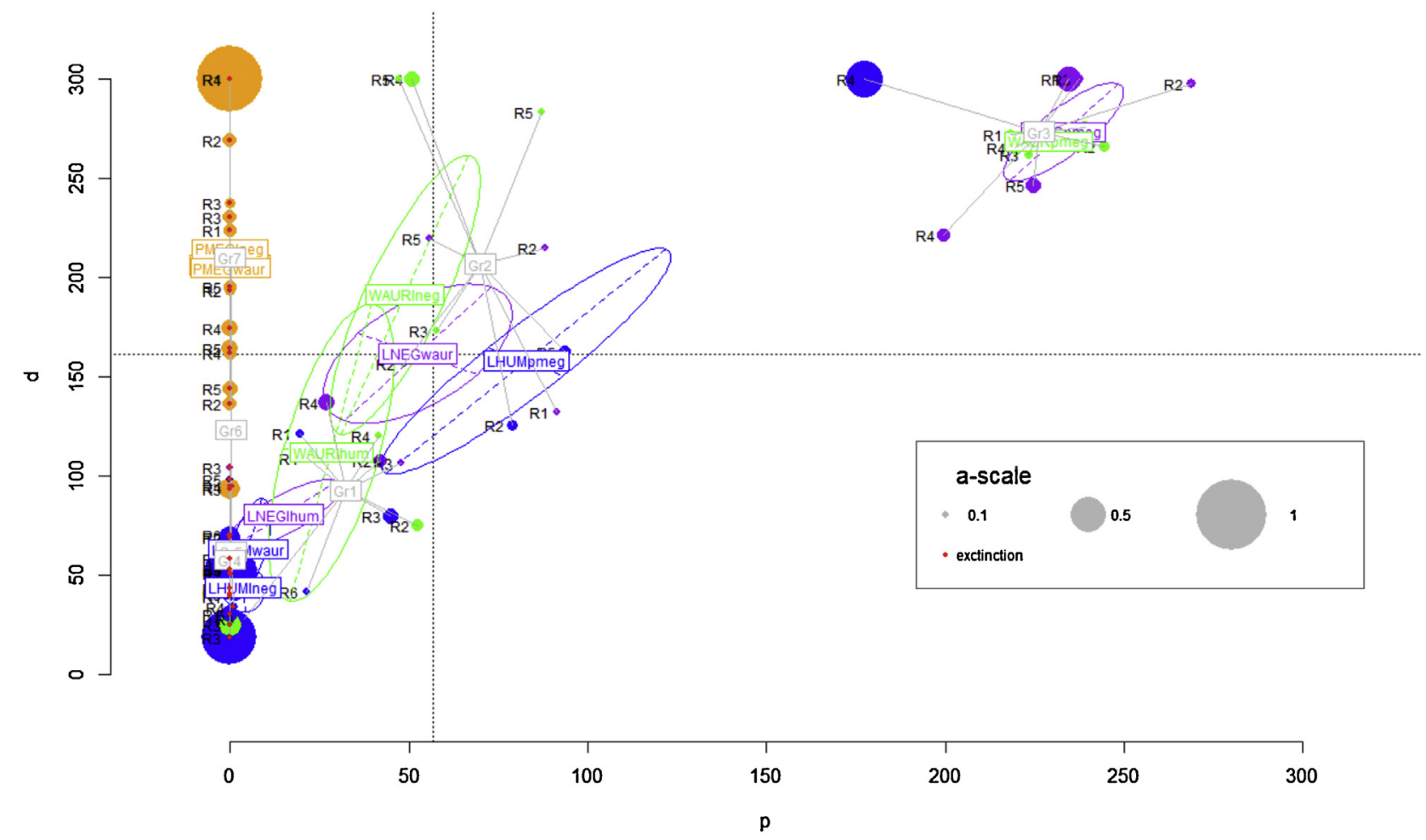

Fig. 3. $2 \mathrm{D}$ representation of the three estimated model parameters that describe the colony survival after confrontation. $d$ is the initial survival after day $0, p$ is the final survival by the end of the experiment, and the size of the coloured disc is proportional to parameter $a$ (the speed of mortality throughout the 42 days; the larger the circle, the faster the mortality; the red dot indicate eventual extinction). The colour of the circles and the labels indicates the focal species.

initial mortality on the first day of interaction was comparatively low. Interactions among the three other species showed more complex dynamics. In all three pairwise interactions, both opponents "won" the interaction in at least one replicate (i.e. had a higher final colony size than the opponent). As different replicates of the same interaction followed different dynamics, it would not be representative to simply average the survival data across replicates. Instead, models were fitted for each colony individually and then the estimated parameters were represented in a parameter space, allowing the analysis of clusters of survival dynamics. This captured more accurately the central tendency of each species interaction, while acknowledging for variability. Generally, W. auropunctata and L. neglectus were the most dominant species and $L$. humile tended towards extinction in all interactions with them. L. neglectus was slightly less competitive than $W$. auropunctata. Overall, this dominance hierarchy is generally consistent with the results found in classical dyadic interference interactions between individuals and small groups of workers (Bertelsmeier et al., 2015a). Behavioural experiments using 1:1 worker interactions have shown that the two high-ranking species, W. auropunctata and L. neglectus, use mainly chemical defences, while the two lower-ranking species use mainly physical defences when paired with one of the three other species (Bertelsmeier et al., 2015a). It is notable that the most dominant species, W. auropunctata, has also the smallest body size.
Our results demonstrated variable dynamics, rendering the outcome of pairwise species interactions less predictable. Interestingly, a steep decrease in colony size was followed by a slower decrease over several weeks in all interactions and replicates. These dynamics observed at the wholecolony level would not be possible to predict based on classical worker-worker interactions. To our knowledge, this is the first medium-term experiment with invasive ants recording the dynamics of colony interactions on a daily basis.

The four species varied strongly in their exploratory behaviour when the adjacent colonies were connected. In particular $P$. megacephala and $L$. humile invaded rapidly the arena of the opponent species, leading to a high proportion of fights occurring on the territory of the opponent. In contrary, W. auropunctata and L. neglectus were slower, more passive explorers. Interestingly, the species with the highest tendency to invade the opponent's territory suffered the highest mortality. This suggests that the two species with strong exploratory behaviour were less competitive through interference. This strong exploratory behaviour, however, might however confer an advantage through exploitation competition.

In native ant communities, one factor promoting coexistence between species is a trade-off between the species' ability to discover and their ability to dominate resources (Lebrun \& Feener, 2007; Parr \& Gibb, 2012; Cerdá et al., 


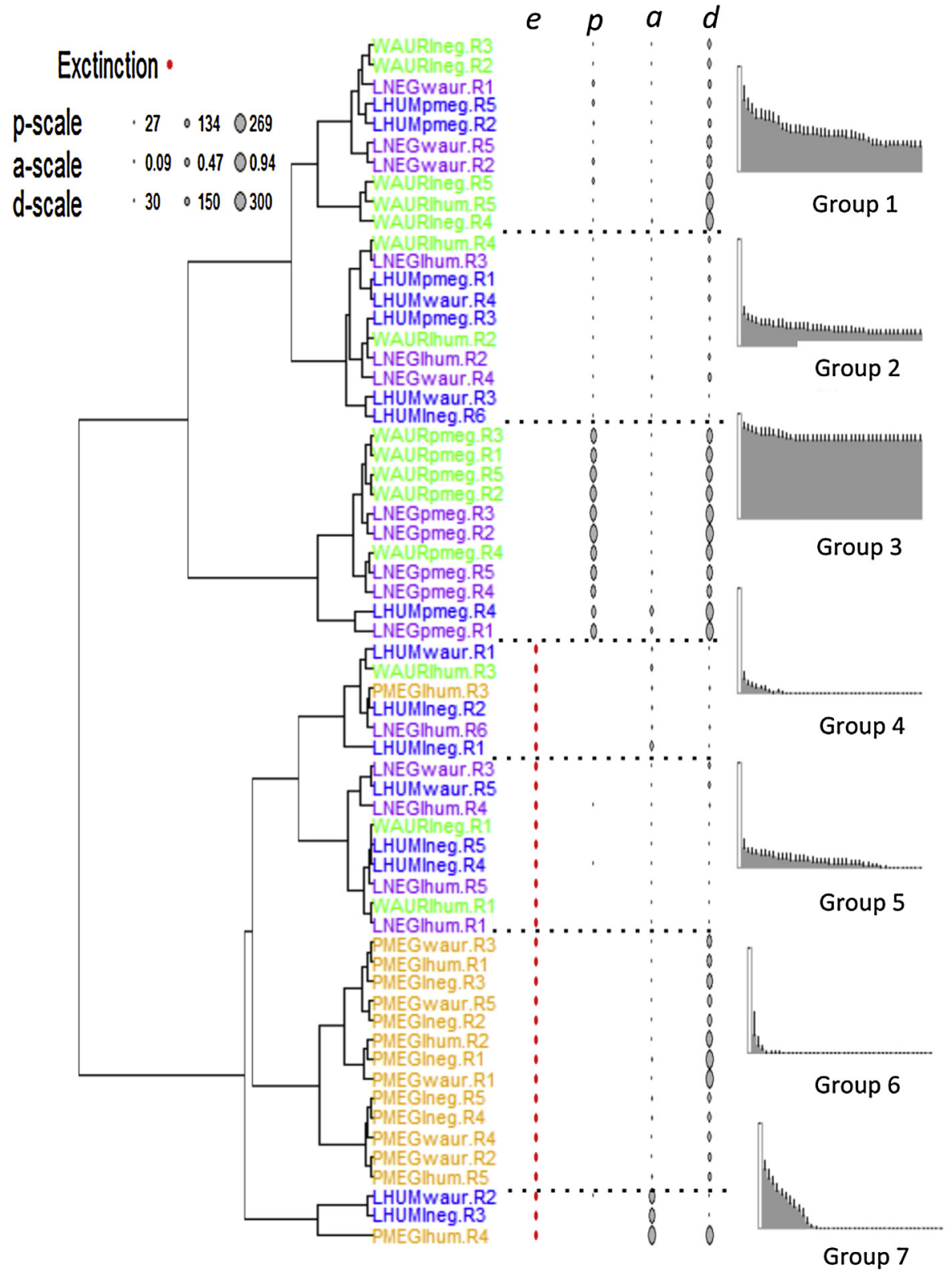

Fig. 4. The classification analysis of the model parameters discriminated 7 groups with similar survival processes. The parameters ( $p, a$ and $d$, plus $e$ for extinction) are represented next to each replicate. The species for which the model has been fitted is written in capitals, its opponent in lower case. R1 to R6 indicate the identity of the replicate. The mean pattern of each group of time series is shown.

2013). However, it has been suggested that invasive ants can break this discovery-dominance trade-off by excelling at discovering and dominating resources (Holway, 1999). This is thought to be an important mechanism leading to their high impacts on native communities by competitively displacing many species (Holway, 1999). Future research may investigate whether there is such a trade-off among invasive ants and whether all of them generally break the trade-off relative to native species.

Although experiments at the whole colony level offer greater realism than behavioural observations over a few minutes in petri dishes, they still suffer from certain limitations. For example, the degree of resource dispersion and habitat complexity (Sarty, Abbott, \& Lester, 2006), as well as habitat type or disturbance can modify dominance hierarchies (Parr \& Gibb, 2010; Cerdá et al., 2013). In addition, the space where adjacent colonies could interact was constrained by the experimental set-up and colonies may not fight so intensely if they were located a few meters apart. However, previous studies have shown that invasive ants can even have impacts on native species at a biogeographic scale, creating a mosaic distribution without co-existing locally (Gotelli \& Arnett, 2000). This type of mosaic distribution can also be observed among dominant native ant species (Ribas \& Schoereder, 2002; Le Breton 2003). Therefore it is likely, that even if the nests were spaced further apart than in our laboratory experiment, 
the species would not co-exist closely, within the same local community.

Further, different climatic suitability of a certain area can favour one species over the other, giving a competitive advantage to one species over another (ex. Spicer Rice \& Silverman, 2013; Barbieri, Grangier, \& Lester, 2015). Such a dominance shift is especially likely in species pairs that do not differ much in their capacity to dominate (e.g., $L$. neglectus and L. humile). Additionally, biotic interactions can alter dominance hierarchies, for example the presence of phorid flies can compromise the competitive abilities of some ant species but not others (Lebrun \& Feener, 2007). Field experiments could be useful to determine the relative dominance of entire colonies under a given set of environmental conditions, using secure, artificial nests for example to guarantee biosecurity (Luque et al., submitted). So far, field-based observations have only been possible at contact zones of two invasion fronts. For example, observations from ranges where two invasive ant species come in contact show competitive exclusion and displacement of one invasive ant by another at a local scale. Examples include the mutual exclusion of L. humile and Solenopsis invicta in the Southern US (LeBrun et al., 2007), L. humile and P. megacephala in Hawaii (Krushelnycky \& Gillespie, 2010) and Bermuda (Lieberburg, Kranz, \& Seip, 1975), L. humile and Pachycondyla chinensis in the US (Spicer Rice \& Silverman, 2013) and W. auropunctata and P. megacephala in New Caledonia (Chazeau et al. 2000, Le Breton 2003). Studies investigating competitive relationships in the field have the advantage that they take place under more realistic environmental conditions than lab-based studies, yet, they also have the disadvantage that they do not allow following the number of individuals at a daily basis over several weeks, which we did here, enabling us to precisely characterize the processes of survival and decline in the competing colonies. Evidence from lab experiments and field observations complement each other nicely and we encourage further studies at invasion fronts.

Another interesting question is how different initial colony sizes would impact the outcome of colony-colony competition. Is there a certain ratio at which dominance would be inversed or a clear winner can be predicted in cases where the hierarchy was not clear-cut at equal group size? For example, established supercolonies of $L$. humile may outcompete smaller incipient L. neglectus colonies in the field, if they have a numerical advantage. Further, the effect of a 'resident' colony versus an arriving colony might be investigated. Models of habitat relative suitability (Bertelsmeier, Luque, \& Courchamp, 2013; Bertelsmeier et al., 2015b) based on correlative predictions of suitable areas cannot take into account a 'resident' effect, i.e. sequential arrival of invasive species. Yet, it seems appropriate to investigate competition between two colonies among the four invasive species, which all reproduce by budding (i.e. dispersal of a newly mated queen and workers on foot), extending and covering slowly the entire area (Rabitsch, 2011). In this way, small newly established colonies of different species can come in contact and compete with each other.

Predicting the winner of a symmetrical colony-colony interaction is not as straightforward as predicting the winner of a worker-worker interaction (e.g. Buczkowski \& Bennett, 2008; Kirschenbaum \& Grace, 2008; Blight et al., 2010; Bertelsmeier et al., 2015a). This study shows the importance of scaling up to the colony level in order to gain realism in predicting the outcome of multiple invasions and in better understanding interspecific competition as the driver of ant community structure.

\section{Acknowledgements}

This paper was supported by Région Ile-de-France (032010/GV-DIM ASTREA), ANR (2009 PEXT 010 01) and BiodivERsa Eranet grants, FFII Project.

\section{Appendix A. Supplementary data}

Supplementary data associated with this article can be found, in the online version, at http://dx.doi.org/10.1016/ j.baae.2015.09.005.

\section{References}

Barbieri, R. F., Grangier, J., \& Lester, P. J. (2015). Synergistic effects of temperature, diet and colony size on the competitive ability of two ant species. Austral Ecology, 40, 90-99.

Beale, E. (1960). Confidence regions in non-linear estimation. Journal of the Royal Statistical Society, 22B, 41-88.

Bertelsmeier, C., Avril, A., Blight, O., Confais, A., Diez, L., Jourdan, H., et al. (2015). Different behavioural strategies among seven highly invasive ant species. Biological Invasions, 17, 2491-2503.

Bertelsmeier, C., Luque, G. M., \& Courchamp, F. (2013). Increase in quantity and quality of suitable areas for invasive species as climate changes. Conservation Biology, 27(6), 1458-1467.

Bertelsmeier, C., Luque, G. M., Hoffmann, B. D., \& Courchamp, F. (2015). Worldwide ant invasions under climate change. Biodiversity and Conservation, 24, 117-128.

Blight, O., Provost, E., Renucci, M., Tirard, A., \& Orgeas, J. (2010). A native ant armed to limit the spread of the Argentine ant. Biological Invasions, 12(11), 3785-3793.

Buczkowski, G., \& Bennett, G. W. (2008). Aggressive interactions between the introduced Argentine ant, Linepithema humile and the native odorous house ant, Tapinoma sessile. Biological Invasions, 10(7), 1001-1011.

Cerdá, X., Angulo, E., Caut, S., \& Courchamp, F. (2012). Ant community structure on a small Pacific island: Only one native species living with the invaders. Biological Invasions, 14(2), 323-339.

Cerdá, X., Arnan, X., \& Retana, J. (2013). Is competition a significant hallmark of ant (Hymenoptera: Formicidae) ecology? Myrmecological News, 18, 131-147. 
Chazeau, J., Potiaroa, T., Bonnet de Larbogne, L., Konghouleux, J., \& Jourdan. (2000). La "fourmi électrique" Wasmannia auropunctata (Roger) en Nouvelle-Calédonie: Expression de l'invasion, moyens d'une maî trise de la nuisance en milieu agricole, praticabilité d'une préservation des milieux naturels. Convention Territoire de Nouvelle-Calédonie/IRD, 1999, 10-63.

Dussutour, a., \& Simpson, S. J. (2008). Description of a simple synthetic diet for studying nutritional responses in ants. Insectes Sociaux, 55(3), 329-333.

Essl, F., Dullinger, S., Rabitsch, W., Hulme, P. E., Hülber, K., Jarošík, V., et al. (2011). Socioeconomic legacy yields an invasion debt. Proceedings of the National Academy of Sciences of the United States of America, 108(1), 203-207.

Gotelli, N., \& Arnett, A. (2000). Biogeographic effects of red fire ant invasion. Ecology Letters, 3(4), 257-261.

Guisan, A., \& Thuiller, W. (2005). Predicting species distribution: Offering more than simple habitat models. Ecology Letters, 8(9), 993-1009.

Holway, D. (1999). Competitive mechanisms underlying the displacement of native ants by the invasive Argentine ant. Ecology, 80(1), 238-251.

Holway, D. A., \& Suarez, A. V. (2004). Colony-structure variation and interspecific competitive ability in the invasive Argentine ant. Oecologia, 138(2), 216-222.

Holway, D., Lach, L., Suarez, A., Tsutsui, V., \& Case, N. D. T. J. (2002). The causes and consequences of ant invasions. Annual Review of Ecology and Systematics, 33(1), 181-233.

IUCN SSC Invasive Species Specialist Group. (2012). Global invasive species database. http://www.issg.org/database/welcome/

Kirschenbaum, R., \& Grace, J. K. (2008). Agonistic responses of the tramp ants Anoplolepis gracilipes, Pheidole megacephala, Linepithema humile, and Wasmannia auropunctata (Hymenoptera: Formicidae). Sociobiology, 51(3), 673683.

Krushelnycky, P. D., \& Gillespie, R. G. (2010). Correlates of vulnerability among arthropod species threatened by invasive ants. Biodiversity and Conservation, 19(7), 1971-1988.

Lach, L., \& Hooper-Bui, L. M. (2010). Consequences of ant invasions. In L. Lach, C. L. Parr, \& K. L. Abbott (Eds.), Ant ecology (pp. 261-286). Oxford: Oxford University Press.

Le Breton, J. (2003). Etude des interactions entre la fourmi Wasmannia auropunctata et la myrmécofaune: comparaison d'une situation en zone d'introduction: la Nouvelle-Calédonie et d'une situation en zone d'origine: la Guyane Française ( $\mathrm{PhD}$ thesis). Université Paul Sabatier Toulouse 3.

Lebrun, E. G., \& Feener, D. H. (2007). When trade-offs interact: Balance of terror enforces dominance discovery trade-off in a local ant assemblage. Journal of Animal Ecology, 76(1), $58-64$.
LeBrun, E. G., Tillberg, C., Suarez, V. A., Folgarait, V. P. J., Smith, C. R., \& Holway, D. A. (2007). An experimental study of competition between fire ants and Argentine ants in their native range. Ecology, 88(1), 63-75.

Lieberburg, I., Kranz, P., \& Seip, A. (1975). Bermudian ants revisited: The status and interaction of Pheidole Megacephala and Iridomyrmex Humilis. Ecology, 56, 473-478.

Lowe, S., Browne, M., Boudjelas, S., \& De Poorter, M. (2000). 100 of the world's worst invasive alien species $-A$ selection from the global invasive species database.

Masciocchi, M., Farji-Brener, A. G., \& Sackmann, P. (2009). Competition for food between the exotic wasp Vespula germanica and the native ant assemblage of NW Patagonia: Evidence of biotic resistance? Biological Invasions, 12(3), 625-631.

Miravete, V., Roura-Pascual, N., Dunn, R. R., \& Gomez, C. (2014). How many and which ant species are being accidentally moved around the world? Biology Letters, 10, 20140518. http://dx.doi.org/10.1098/rsbl.2014.0518

Parr, C., \& Gibb, H. (2010). Competition and the role of dominant ants. In L. Lach, C. Parr, \& K. Abbott (Eds.), Ant ecology (pp. 77-96). Oxford: Oxford University Press.

Parr, C., \& Gibb, H. (2012). The discovery-dominance trade-off is the exception rather than the rule. Journal of Animal Ecology, $81,233-241$

Pimentel, D., Zuniga, R., \& Morrison, D. (2005). Update on the environmental and economic costs associated with alien-invasive species in the United States. Ecological Economics, 52(3), 273-288.

Rabitsch, W. (2011). The Hitchhiker's guide to alien ant invasions. BioControl, 56(4), 551-572.

Ribas, C., \& Schoereder, J. (2002). Are all ant mosaics caused by competition? Oecologia, 131(4), 606-611.

Spicer Rice, E., \& Silverman, J. (2013). Propagule pressure and climate contribute to the displacement of Linepithema humile by Pachycondyla chinensis. PLoS ONE, 8(2), e56281.

Sarty, M., Abbott, K. L., \& Lester, P. J. (2006). Habitat complexity facilitates coexistence in a tropical ant community. Oecologia, 149(3), 465-473.

Suarez, A. V., McGlynn, T. P., \& Tsuitsui, N. D. (2010). Biogeographic and taxonomic patterns of introduced ants. In L. Lach, C. L. Parr, \& K. L. Abbott (Eds.), Ant ecology (pp. 233-244). New York, NY: Oxford University Press.

Suarez, A. V., Holway, D. A., \& Ward, P. S. (2005). The role of opportunity in the unintentional introduction of nonnative ants. Proceedings of the National Academy of Sciences of the United States of America, 102(47).

Tanner, C. J., \& Adler, F. R. (2009). To fight or not to fight: Contextdependent interspecific aggression in competing ants. Animal Behaviour, 77(2), 297-305.

Available online at www.sciencedirect.com 